\title{
El problema nacional de América lati- na y ciertos esquemas de integración regional
}

\begin{abstract}
A r t U R O FrONDiz I fuc Presidente de la Repúblicá Argen. tina durante 1958-1962. Anteriormente electo Diputado nacional por la Unión Cívica Radical en el distrito de la Capital Federal desde 1946 hasta 1952.

En 1951 su particlo lo consagró candidato a la Vicepresidencia de la República y electo Presidente en las elecciones del 23 de febrero de 1958, reuniendo más de 4 millones de votos contra 2.500 .000 de su adversario.

Depuesto por un Golpe Militar del 29 de marzo de 1962.

En la actualidad, preside el Centro de Estudios Nacionales (Buenos Aires), que cumple una labor de investigación y difusión cultural.

Sus principales publicaciones incluyen: Régimen Juridico de la Economia Argentina, 1941; Petróleo y Polftica, 1956; Hacia la gran siderurgia nacional, 1958; Presidencia (tres tomos), 1958; Petróleo y Nación, 1963; Politica Económica Nacional, 1963; El problema Agrario Argenlino, 1965; Estrategia y Tálica del Movimienlo Nacional, 1964; La Cueslión Dominicana y la Soberania Argentina, 1965; El Mundo del Futuro, 1966.
\end{abstract}

Las decisiones sobre el desarrollo económico que se toman en un país, .especialmente por el gobierno, tienen significado y consecuencias que exceden la esfera puramente económica. Influyen en la consolidación de la personaliclad nacional, en la soberanía, en la paz interior, en la promoción del nivel de vida del pueblo, en la cultura, en la educación, en la salud espiritual de la comunidad. En una palabra, afectan a la sociedad en todas sus expresiones.

De esta universalidad de la política económica se desprende que no se la puede determinar como acción aislada de su contexto sociopolítico ni como práctica dictada por exclusivas razones técnicas. Una determinada solución o enfoque económico puede ser inobjetable a la luz de la ciencia de la economía política pero inconveniente si la juzgamos en función de la política nacional como un todo.

Por ejemplo, es sabido que la base del crecimiento sostenido de una economía nacional es la acumulación de recursos para financiar- 
lo, recursos que, fundamentalmente, son provistos por el ahorro interno. La tasa de acumulación de este ahorro dependerá de las didas de política económica que se adopten en materia de ingresos, o sea aquellas medidas que produzcan una contracción del consumo en beneficio de la expansión del ahorro y de las inversiones reproductivas. Una política nacional global no puede dejar de computar los efectos sociales de ese desplazamiento de ingresos del sector de consumo al sector de capital. Pudiera ser peligroso e injusto sacrificar en demasía a los consumidores, sobre todo cuando el nivel de consumo popular es, de por sí, bajo. Por otra parte, una política drástica de reducción del consumo en favor de la acumulación presupone un grado de consenso y/o de compulsión de la comunidad que se da solamente en procesos revolucionarios que significan trastrocar totalmente las instituciones y el derecho de propiedad. Puesto que éste no es el caso de las repúblicas latinoamericanas, la política de ingresos y de formación del ahorro interno está limitada por la misma indole de sus sistemas sociales y jurídicos. Como veremos más adelante, la alternativa a la compulsión para formar el ahorro interno es recurrir, en el mayor grado posible, a los ingresos provenientes de la cooperación financiera externa. La opción es materia de decisión polftica global y no específicamente técnica.

Otro ejemplo muy aplicable a la situación latinoamericana y sobre el que nos extenderemos en este estudio, es el de la complementación o integración regional de las economías de nuestros países.

Los conceptos específicamente económicos de economías de escala, dimensión del mercado y dimensión de las empresas y de costos comparativos y de economicidad, abonarían la conveniencia aparente de algunos esquemas de división internacional del trabajo entre nuestras repúblicas. Estos esquemas son atrayentes y conforman a los técnicos inclinados a las soluciones macroeconómicas en boga. Son, además, coherentes con la experiencia mundial de los monopolios de la gran industria cuyas estructuras trascienden las fronteras nacionales. (El caso típico es la Comunidad del Carbón y del Acero en Europa). No es del todo extraño que los economistas que sólo manejan consideraciones propias de su ciencia, aconsejen trasplantar en pequeño esta experiencia a nuestras naciones. Es también lógico que los dirigentes cle la banca internacional y de las naciones que ejtán en condiciones de prestar colaboración al desarrollo latinoamericano, entiendan que sería muy conveniente concentrar los fondos disponibles en la financiación de grandes proyectos regionales en lugar de dispersarlos en proyectos nacionales, algunas veces duplicados. 
Sin embargo, como veremos, tales teorias tropiezan con su inadaptabilidad a las necesidades y aspiraciones de los pueblos subdesarrollados, tanto en América como de otros continentes. No solamente porque es diametralmente diversa la estructura de nuestras economías en formación de las economías plenamente integradas de Europa occidental, sino porque la integración regional de Europa no estorba ni se sobrepone a la consolidación de esas nacionalidades maduras, mientras que en nuestro caso la integración regional, con ese alcance, veridría a postergar y a frustrar la formación plena de nuestras incipientes nacionalidades. Lo que en el primer caso es superación en el segundo sería renunciamiento. Aquí también, la razón meramente técnica no satisface las razones de una política nacional total.

Por consiguiente, deseo aproximarme al tema desde mi posición de político a quien preocupa.la estrategia del desarrollo económico como arma en la lucha por reafirmar las raíces profundas de la nacionalidad, que no es un concepto retórico ni estático. La formación de la nacionalidad es un proceso complejo y dinámico, de esencia histórica irrenunciable. Se asienta en el desarrollo económico nacional pero sus frutos no son simplemente materiales. En el marco del crecimiento de las fuerzas productivas ocurren e interactúan fenómenos sociales y culturales cuyo conjunto conforman la existencia de una nación, a saber:

a) El ascenso homogéneo de los niveles de vida de las diversas regiones y provincias;

b) La alianza de todos los sectores sociales en la empresa de construir la nación;

c) La integración social, económica y cultural del país, de modo de formar la unidad histórica que es la nación, con sus expresiones espirituales propias;

d) La justicia social, que es fruto del desarrollo y de una política deliberada de distribución de ingresos;

e) La soberanía, como signo de autodeterminación nacional y de liberación de factores externos que traben el desenvolvimiento independiente de la comunidad, $y$

f) La capacidad creciente del país de integrarse, con pleno derecho a la igualdad de oportunidades, en la comunidad universal moderna, para contribuir eficazmente a la expansión multilateral de los intercambios comerciales y culturales y a la preservación de la paz y ia convivencia entre todos los pueblos del mundo. 
Estos factores y otros muchos que caben en el enunciado genérico establecen la diferencia entre una nación y una colonia o una factoría. La abundancia material y la aplicación de cualquier esquema que signifique diluir la nación en una gran unidad hemisférica podrían. de ser factibles esas teorías, hacer de cada una de las uniclades de la región una pieza de un conglomerado latinoamericano. Pero no harian de ellas una nación, ni tampoco sería Latinoamérica una nación, en la idea bolivariana. Porque esta hipotética nación-continente sería el agregado de cuerpos indiferenciados y sin esencia histórica; una mezcla, mas no una personalidad. Suponer lo contrario sería negar la experiencia de todas las sociedades humanas y la nuestra en particular. Nuestras naciones, nuestros proyectos nacionales, no son resultado del azar ni de decisiones arbitrarias, sino producto de la historia, como son todas las formaciones nacionales. En este contexto histórico irreversible es donde debemos colocar la problemática total de nuestros procesos nacionales tanto en el aspecto material del desarrollo económico como en los infinitos aspectos sociales y espirituales que establecen la idea de nación.

Es menester insistir en la crítica a esta concepción supranacional de la integración latinoamericana porque, explícitamente o de modo tácito, ha sido propuesta como la vía ideal para alcanzar las metas del desarrollo de nuestros países. Conviene señalar, de paso, que esta tesis supranacional aplicada a la economía se corresponde con la tesis política de la supranacionalidad en materia de seguridad. Uno de sus expositores, el ex ministro de Relaciones Exteriores de Brasil, mariscal Juracy Magalhaes, se atrevió a sostener, en abono de su proyecto de creación de una policia continental de la OEA, que la idea de soberanía era un perimido resabio del siglo diecinueve. Su sucesor en Itamaraty, señor Magalhaes Pinto, ha desechado el proyecto y su filosofía, y ha recibido el auspicio de la mayoria de los jefes de las fuerzas armadas. No obstante, dentro y fuera de América latina, se sigue propugnando la nacionalidad latinoamerioana como forma superior y avanzada de nuestro fraccionamiento nacional.

Digamos, para ser ecuánimes, que esta concepción de los grandes espacios supranacionales, que llega hasta propiciar un gobierno mundial, no es nueva ni exclusiva de los teóricos latinoamericanos de la nacionalidad regional. La verdad es que se trata de una utopía de vieja data y de ancestro universal. Podríamos llamarla una construcción "perimida" del liberalismo decimonono aunque reconoce raíces en las utopistas de la antigüedad. Actualmente existe una caracteriza- 
da corriente de europeistas que, encandilados por el éxito de la integración económica de Europa occidental, quieren transformar este gran cartel en unión política absoluta.

Es súgestivo que se exhume este sueño de ántigúos pensadores precisamente en nuestra época, caracterizada por la vasta revolución liberadora $\dot{y}$ nacionalista de las ex colonias de Asia y Africi. Parecería un desafío del pensamiento de los centros mundiales de poder a esta insurgenicia nacional de sus antiguos súbditos. Y esta idea politica de la supranacionalidad no es extraña al proceso. de enorme concentración de capital, tecnología y mecanismos comerciales en manos de los grandes monopolios. Con sus acuerdos sobre precios y mercados, con sus empresas multinacionales que traspasan las fronteras, los monopolios mundiales proceden con entera lógica cuando desean crear instituciones políticas acordes con su extraterritorialidad económica. Los grandes espacios económicos, tendrian asi su superes: tructura política.

A pesar de que en Europa parecerían clarse las condiciones materiales de un proceso unificador, puesto que existen polos regionales de producción tan concentrados como el de la cuenca siderometalúrgica del Ruhr, no progresa allí la idea del estado supranacional. $\mathrm{Ni}$ siquiera han consentido sus diversos países esquema alguno de complementación o división internacional del trabajo. En el sector occidental, Italia y España, naciones tradicionalmente agrarias, no se han resignado al papel de proveedoras de productos de la tierra en el mercado regional. Hacen ingentes esfuerzos por industrializarse y emular los niveles tecnológicos de Francia, Alemania o Gran Bretaña. En el sector oriental, donde el comecon se planeó como unidad cerrada del bloque socialista destinada a repartirse los sectores de producción, cada nación está haciendo su integracción propia y aumenta sus intercambios con las naciones capitalistas. Rumania incluso rompió el cerco creado por los regímenes socialistas en torno a Alemania occidental y ha entablado relaciones con Bonn, con cuyo gobierno celebró tratados de comercio e intercambio cultural. No ha sido suficiente el rigor de la disciplina ideológica para contener la expansión de la personalidad nacional independiente.

Entre los países socialistas del Este de Europa, Yugoslavia ofrece otro ejemplo de independencia. País tradicionalmente agrario y atrasado ha evolucionado tenazmente hacia las formas avanzadas de lia producción industrial y expande sus exportaciones hacia los mercados capitalistas. Para financiar su desarrollo ha logrado préstamos e inversiones internacionales de todo origen. Su parlamento aprobó recientemente una ley de radicación de capitales extranjeros, por la cual se 
admite la asociación de inversores del exterior con las empresas nacionales. Previa aprobación legislativa, dichos capitales externos pueden tener mayoria en las empresas; si el aporte no sobrepasare el $49 \%$ del acervo accionario no se requiere autorización estatal. La ley prevé garantías contra expropiaciones y autoriza las remesas de utilidades al exterior para pagar a los accionistas extranjeros. Solamente están al margen de este régimen las empresas de servicios públicos, de defensa nacional y el comercio, que quedan reservados al capital nacional. En cambio, se alientan las inversiones extranjeras en todos los rubros de la producción, con el fin de expandirla y modernizarla para que alcance niveles competitivos en el mercado. mundial. Los dirigentes yugoslavos entienden que la cooperación financiera internacional, lejos de amenazar la autodeterminación de la sociedad socialista contribuye a acelerar el proceso de integración nacional que es la base de una independencia efectiva. Yugoslavia ha resistido -como $\mathrm{Ru}$ mania- el esquema de la división internacional del trabajo en el bloque socialista que fue el pensamiento primitivo del comecon.

Al revés de lo que profetizaron los utopistas, el mundo del siglo veinte que ya pisa los umbrales del veintiuno, no ha contemplado el eclipse de la idea nacional. La universalización del conocimiento, la proyección del genio del hombre en el espacio interestelar, la difusión extraordinaria de insospechadas técnicas productivas, no solamente no han uniformado el mundo ni impuesto sobre él una voluntad centralizadora, sino que han contribuido a enriquecer la diversidad, a crear oportuniclades de desenvolvimiento para todas las personaliclades macionales. El proceso hacia la convivencia, hacia la unidad y la paz evoluciona sobre los carriles de una profundización de la autodeterminación nacional. Es una síntesis de lo diverso y lo genuino de cada ser nacional, más universal cuanto más autóctono, como en el arte:

Esto ocurre en el hemisferio norte del planeta, territorio donde se concentran los frutos de la ciencia y la cultura y donde se produce la casi totalidad de los productos industriales que circulan en el mundo. Esto se produce en un espacio geográfico cuyos habitantes gozan de niveles de vida homogéneos, donde no existen casi zonas atrasadas o marginadas dél ciclo productivo y del consumo. Ocurre en un continente habituado a la frecuentación e intercambio de las culturas nacionales, cuyos pueblos tienen la secular vivencia de sentirse miembros de un todo llamado Europa. En ese todo hereditario, cada nación lucha por conservar esta condición y por emular a las demás, sin perjuicio de coordinar sus economías de modo que tal coordinación estimule $y^{\prime}$ fortifique la posición propia. El Mercado Común Europeo es una integración de naciones integradas, cuyo objetivo es acelerar $\mathrm{cl}$ 
Arturo Frondizi / El problema nacional de América Latina y ciertos esquemas de integración regional

desarrollo común sin desmedro del desarrollo de todos los pueblos que lo forman.

En el mundo de las potencias adelantadas no solamente no ha decaído la idea de nación, sino que se vigoriza. Al vasto munclo subdesarrollado se le ofrece un proyecto supranacional, presentado como superación de la idea "arcaica" de la soberanía.

Las naciones a las que se propone este proyecto no son todavía naciones. Las de Asia y Africa apenas salen de la relación colonial. Las de América latina no han conseguido la integración material y la independencia de factores externos que sustenten la libertad política conquistada hace siglo y medio.

\section{El SUBDESARROLLO LATINOAMERICANO}

El subdesarrollo de América latina se expresa en los siguientes rasgos, entre otros:

a) Extensos territorios inexplotados, fraccionamiento continental por falta de comunicaciones y transportes; similar incomunicación entre regiones y provincias de un mismo país;

b) Rígida estratificación social en la mayor parte de las repúblicas; población dedicada preponderantemente a la minería y la industria agropecuaria explotada a muy bajos niveles tecnológicos; urbanización incipiente; condiciones primitivas de las comunidades rurales; ingresos de subsistencia en grandes sectores; escaso proletariado industrial;

c) Industrialización progresiva de algunos países, pero limitada a la industria liviana; escasos centros de producción enengética y de la industria pesada; dependencia del abastecimiento externo de materias primas industriales, combustibles y maquinaria; baja productividad por atraso tecnológico e insuficiencia de capital; baja tasa de ahorro interno y de inversiones;

d) Incapacidad crónica de financiamiento del desarrollo interno por virtud del proceso progresivo de deterioro de la relación de intercambio; por la misma razón, transferencia constante de ingresos hacia los centros mundiales desarrollados y disminución consiguiente de las reservas de oro y divisas; inflación determinada primordialmente por el déficit del comercio $y$ la balanza de pagos; hipertrofia del sector público improductivo que absorbe así la fuerza de trabajo desocupada;

e) Constante degradación del salario real; desocupación agravacla por el éxodo de la población campesina a las ciudades; déficit crónico habitacional y. de servicios; tensiones sociales en aumento. 
Faltan pues, en nuestra América, las bases mínimas de integración nacional y', con mayor razón, las de integración regional. El continente es un conjunto de ínsulas, desconectadas entre sí; cada país es un conjunto de otras ínsulas, sus regiones y provincias. No hay niveles homogéneos de vida social y cultural. La economía entera de la región se empobrece crecientemente por razón de su dependencia de mercados externos cada vez menos accesibles a nuestros productos. Vivimos para el exterior, pero en una relación por la cual el exterior es incapaz de suministrarnos los recursos indispensables para mantener el crecimiento sostenido de nuestros países y satisfacer las necesidades de nuestra población en una era de contagiosas expectativas de progreso.

\section{Complementación regional}

Sobre esta estructura básica cre cesconexión, aislamiento, deterioro alarmante cle los niveles de vida, se nos invita a superponer esquemas de integración regional que vendrían a suplir los procesos nacionales de integración. En lugar de llegar a la integración regional como etapa superior de las integraciones nacionales, se nos propone comenzar de arriba para abajo: los proyectos multinacionales descenderían milagrosamente sobre nuestras clébiles estructuras nacionales para vigorizarlia.

Estos proyectos multinacionales se desenvolverian conforme a un plan de división internacional del trabajo entre nuestros países. Se formarian a lo lango de América latina grandes "polos de crecimiento" - "centros" productivos diferenciados; la pauta para la distribución geográfica de clichos centros sería la economicidad. Habría asi, centros mineros, centros agropecuarios, centros de industria pesada, centros de inclustria liviana, con prescindencia de fronteras nacionales. El mercado de consumo para estos "polos" o "centros" productivos sería América latina como un todo, sin perjuicio de exportar los excedentes, también en común. El reparto de funciones se haría sobre la base de un catastro de recursos continentales. Donde fuera más económico producir cereales y carne, se producirian cereales y' carne. Así sucesivamente para el acero, las máquinas, los vehículos. Técnicamente, las rentaj:is serian consiclerables: concentración de inversiones y mercado único con suficiente magnitud para abso-ber toda la producción así planificada.

Conrengamos en que esta teoría no es tan absoluta como surge de esta síntesis. Se aclmiten alteraciones parciales y la aceptación de situaciones preexistentes. Sin embargo, la línea general es ésa. 
Reiteramos un juicio anterior: el programa luce impecable si permanecemos en el campo de la teoría. No faltan los técnicos que califican de utópico el plan, sin embargo. Tienen razón, porque no hay planes divorciados de los presupuestos de la realidad ya la hemos visto sobre qué realidad tendrían que aplicarse. Una programación de este género ha resultado impracticable aun en la estructura altamente concentrada y monopolizada de la industria pesada europea. La comunidad del Carbón y del Acero tropieza con crecientes dificultades para imponer a todos sus miembros las obligaciones referentes a precios y reparto de mercados y se denuncian evasiones y transgresiones frecuentes; se ha clenunciado un contrabando sistemático que consiste en exportar productos de la comunidad al país señalado y reexportarlos clandestinamente a otros fuera del sistema.

Pero dejemos a los economistas la tarea de discutir, en el marco de sus propias ideas y experiencias, la factibilidad de esta integración de gran estilo en un continente inmaduro para emprender tal empresa.

Nosotros insistiremos en enfocarlo desde el ángulo político-social.

Suponiendo que fuera inobjetable el proyecto para los economistas no lo es para quienes nos preocupa ante todo otro proyecto: el proyecto nacional.

\section{IMPERATIVO HISTÓRICO}

Nuestros pueblos latinoamericanos están obligados a consagrar a este proyecto de construcción nacional todas sus energías, sin desviaciones ni sustitutos.

La inserción de las repúblicas latinoamericanas en el sistema económico y social del siglo diecinueve les permitió desenvolver instituciones políticas liberales y una soberanía formal que ocultaban la dependencia material emengente del comercio con los centros industriales de ultramar. Así se consolidaron estructuras socioeconómicas primarias pero estables y bastante coherentes en el lapso comprendido entre las últimas décadas del siglo pasado y las primeras del actual. La relación por la cual nuestros países colocaban en el exterior sus productos minerales y agropecuarios y, a cambio de ellos, importaban bienes industriales, funcionó adecuadamente hasta fines de la primera guerra mundial. Desde esa fecha comienza a perfilarse una crisis que culmina irremisiblemente en nuestros días. Por diversos motivos, ampliamente difundidos por los economistas del desarrollo, la clásica relación de intercambio entre productores primarios y productores de bienes industriales se deteriora en tal grado en perjuicio de los prime- 
ros que ya no pueden subsistir en el marco de dicha relación. Estas naciones en formación comprueban que su misma existencia, sus aspiraciones de progreso e independencia, naufragan por razón de la falencia de su base material económica. Resurge entonces, en nuestros pueblos, el primitivo espíritu revolucionario y liberador de los origenes de la guerra de independencia, aplicado naturalmente a una coyuntura distinta. Pero el riesgo y la aventura son de idéntica naturaleza, pues se trata, hoy, como entonces, de luchar por la preservación de la nacionalidad. Es el mismo proyecto nacional el que está en peligro. Y la más fría y objetiva lógica del análisis económico demuestra que ésta no es una conclusión retórica. Damos aquí por sabidos los extremos concretos y las cifras que señalan el grave peligro de disolución y de frustración que afrontan nuestros pueblos.

El sentimiento de frustración se agrava porque nuestro retroceso ocurre en el cuadro del vertiginoso avance de las naciones que antes fueron nuestras metrópolis políticas $y$ comerciales. Renacidas de la muerte y la clevastación de una guerra total como fue la última, estas naciones europeas han cumplido en veinte años el milagro de reconstruirse integramente $y$ de multiplicar varias veces su potencial económico y social de anteguerra. La economía de Europa occidental compite y'a con la enorme capacidad acumulada por Estados Unidos en las dos guerras mundiales. Italia marca un ejemplo elocuente: derrotada en la guerra, asolada por luchas internas, ha dejado atrás iu condición agraria y hoy es una de las tres grandes naciones del continente. España está en camino de su integración industrial acelerada. Las dos mitades de Alemania superan los efectos de la división y contribuyen poderosamente a la integración de Europa.

No existe impedimento objetivo alguno para que las naciones latinoamericanas emprendan el sendero de su integración nacional. Al contrario, puede afirmarse que las condiciones objetivas favorecen el proceso. La explosión científica y tecnológica y la acumulación de recursos financieros en el sector de naciones adelantadas tienen una inmanencia universal irreprimible. Su dinúmica propia empuja a la universalización, por dos razones. Primera, el factor de clemostración que incita a las naciones rezagadas a la reproducción del progreso de las naciones inclustriales. Segunda, la necesidad de expansión y dc creación de nuevos mercados inherentes al dispositivo de producción del mundo industrial moderno, centuplicado en su productividad y cuyos mercados internos de consumo alcanzan niveles de saturación.

No hay, pues, obstáculos externos que latalmente se opongan a nuestra lucha nacional en la perspectiva histórica. Puede haber y per- 
duran intereses particulares externos que se empeñarán por algún tiempo en retardar la incorporación de nuestros paises al circuito mundial de la producción y el comercio de la era industrial. Son resabios de los intereses colonialistas que medran con nuestra condición de naciones agromineras. Pero estos mismos intereses cumplen en los centros mundiales un papel declinante y pierden fuerza relativa en el conjunto de la economía nacional de esos centros. La materia misma de su comercio (alimentos y materias primas naturales) es una fracción cada día menor en el mecanismo de producción y de cambio mundiales. Tanto la producción como los intercambios internacionales giran preponderantemente dentro del sector de bienes elaborados y de bienes de capital. Computados por valores estos bienes constituyen prácticamente el monto definitorio del valor total del intercambio. La economía mundial está regida por las pautas de este intercambio de bienes industriales crecientemente complejos y variados. El hecho de que muchas naciones europeas estén alcanzando el autoabastecimiento interno de alimentos y que el laboratorio sustituya con artículos sintéticos los metales, el caucho, las fibras y otros productos naturales, reducirá aún más el peso específico del comercio de materias primas y alimentos en el total de los intercambios internacionales.

Nuestras repúblicas enfrentan su crisis en un cuadro mundial que las ayuda a evadirse de su clásica condición de productoras primarias. Que consigan este resultado depende de una decisión de sus pueblos y de sus dirigentes. Se trata de una opción voluntaria, deliberada, eminentemente subjetiva.

En esta subjetividad juegan precisamente los factores nacionales, la vocación de independencia y albedrio, el ansia de los pueblos de superar su atraso, su indigencia material y cultural.

Respondiendo 2 estas exigencias de nuestros pueblos, debemos plantearnos la estrategia del desarrollo.

\section{Consecuencia del esquema de la división del trabajo}

La pregunta clave y la que me propongo contestar es la siguiente:

¿Se satisface el proyecto nacional en el marco de la integración regional que se nos propone, fundada en el esquema técnico de la división del trabajo entre nuestras repúblicas?

Partimos de la base de que nadie ha propuesto hasta ahora seriamente la fusión de nuestras nacionalidades en una nacionalidad y un estado latinoamericano. Simplemente se gira en torno de convenios entre naciones soberanas que consistirian en establecer un sistema 
de distribución de funciones, derechos y obligaciones en el seno de una comunidad económica regional. En este camino, quienes más avanzan, proponen la constitución de órganos de gobierno de esta comunidad, que tendrían poderes supranacionales delegados.

Como hemos dicho, la esencia de este régimen es la distribución de centros regionales y proyectos multinacionales. Su justificación es la necesidad de concentrar recursos y crear un mercado único capaz de absorber la producción asi planificada.

Sin tener en cuenta las fronteras nacionales, América latina se dividiria en regiones geoeconómicas dedicadas cacla una a la especialización más aconsejable por su economicidad.

Un argumento efectista que se avanza para explicar el plan, es que también cada una de nuectras naciones está dividicla naturalmente en diversas regiones productivas y que solamente se trataria de trasladar esta imagen al continente. El simil tendxía sentido si el continente fuera en el futuro una nación, objetivo que no ha sido defendido con demasiada convicción. De modo que el esquema se aplicaría no a regiones de una misma nación sino a naciones independientes unidas en sí mismas. La especialización proyectada congelaría la estructura económica preponderante en cada una cle nuestras repúbliras, trabando así la posibilidad de cada una cle ellas de perseguir su integración nacional propia, es decir, la diversificación de su producción, la elevación homogénea cle niveles materiales y culturales cle su población, la capacidad de generax en cada país la multiplicidacl cle activiclades económicas que es la única garantía de transformación y progreso en el marco nacional. Una nación congelada en la monoproducción o en sectores primarios de producción no llegará nunca a ser una nación autodeterminacla. La relación colonial del pasado seria reemplazada por una relación igualmente mediatizada, esta vez en aras cle la complementación regional.

Los efectos de tal especialización regional son fácilmente predecibles. Podríamos agruparlos grosso modo así:

a) Si la provisión de energía o de productos siderúrgicos o de maquinaria de una de nuestras naciones dependiera de centros o plantas multinacionales instaladas en territorio de otro país, o si la provisión de alimentos para los obreros industriales de un pais depencliera de los abastecimientos importados de otro país, habría que preguntarse cómo operarian los mecanismos supranacionales en caso de que el interés nacional del país productor entrara en conflicto con el clel país consumidor. No es necesario referirse a la hipótesis de un conflicto internacional entre ellos, siempre posible. Bastaría con una contradicción, pasajera o permanente, de intereses, hipótesis más factible 
aún. No puede responderse a esto con el argumento de que ambos estados estarian ligados por los compromisos libremente contraídos en el sistema regional. La experiencia indica, y no puede reprocharse el hecho que el interés nacional -cuando es perentorio e ineludibleprima siempre sobre las obligaciones internacionales. Estas últimas sólo son operativas mientras coinciden los intereses de las partes en el mantenimiento del status internacional concertado. A este respecto, es elocuente la experiencia del Mercado Común Europeo. Dentro del sistema regional y sin perjuicio de los convenios de intercambio y de tarifas, cada nación ha diversificado al máximo su economía, precisamente para no depender de las contingencias de un quebrantamiento de las estipulaciones comunitarias. Inclusive en materia de inversiones tan cuantiosas y de tecnología tan exclusiva como son las cle las industrias cibernéticas, nucleares y espaciales, ningún estado ha renunciado a desarrollarlas dentro de sus fronteras. La resistencia de Francia, Alemania e Italia a suscribir el tratado universal de no proliferación atómica deriva precisamente del deseo de preservar la autodeterminación en las investigaciones y proyectos pacíficos industriales, basados en la energía atómica. Igual resistencia se advierte en las naciones de América latina, con motivo del tratado de México contra la proliferación nuclear;

b) Al planificarse la concentración de la gran industria en "polos de crecimiento" regionales, se concentraría también en torno a estos polos la población obrera calificada. Subsistirian grandes regiones manginadas de esta civilización industrial y dedicadas a las explotaciones primarias o de industria rudimentaria. Países enteros podrían quedar incluidos en estas zonas de producción agrominera. Inclusive se han propuesto a algunos países, como la Argentina, que cancelen o -posterguen sus planes en la industria pesada y concentren las inversiones en la explotación agropecuaria para la cual están especialmente preparados. Sus necesidades de materias primas industriales serían provistas por los centros siderometalúngicos y petroquímicos multinacionales, ubicados en otras repúblicas. Habria, pues, en el continente, sociedades o comunidades altamente evolucionadas y con los niveles propios de la producción industrial y otras comunidades obligadas a desarrollarse al nivel de la vida rural campesina. En una palabra, la división entre naciones industriales y naciones rurales, traslaclada al ámbito de nuestras repúblicas;

c) Este gran esquema de hacer de América latina una soīa unidad productiva, sin consideración de los intereses y las aspiraciones nacionales de sus pueblos, encaja perfectamente en el estilo supranacional de las inversiones y combinaciones en los monopolios de las gxandes 
potencias. Conforme a tal esquema, América latina se convertiría en un ancho espacio complementario de las economías de esos monopolios. Por vía del crédito internacional y de las inversiones directas, el capital monopolista administraría la producción y los intercambios cle esta región clentro de sus planes mundiales globales. En virtud de la concentración y la racionalización que el plan supone, así como de los menores costos de mano de obra, los monopolios exteriores se radicarian en nuestro continente y obtendrían mayores utilidades que en sus países de origen. Ya no estaría en manos de nuestros pueblos y de nuestros gobiernos y productores la política nacional de obtener la cooperación financiera externa y canalizarla a la ejecución de planes nacionales de desarrollo prioritario. las prioridades, las inversiones, su distribución geográfica, su oportuniclad y su magnitud, las cuotas de producción, la regulación cle la oferta y la demanda y de los precios, estarían en manos de órganos supranacionales sometidos a las reglas de juego del capital monopolista internacional. Se cumpliría así, cabalmente, la tesis de la caducidad de las soberanias, sólo que la soberanía habría sido transferida a poderes exteriores. Son obvias las consecuencias de esta delegación de soberanía en materia de producción de elementos vitales para la defensa nacional y el equipamiento de las fuerzas armadas nacionales.

\section{INTEGRACIÓN REGIONAL: ETAPA SUPERIOR}

Estas son algunas de las observaciones de fondo que podrían hacerse a la figura de la integración supranacional. Los economistas tienen otras rescrvas de carácter técnico que no mencionaremos aquí.

Extraería una conclusión apresurada quien supusiera que propugnamos la autarquía, o sea, un aislacionismo nacional de viejo cuño y que somos enemigos de toda integración económica de América latina. Entendemos que se abre amplio campo a la cooperación entre nuestras repúblicas y que es conveniente y necesario concertar arreglos que conduzcan a la vigorización y universalización del sistema de la ALALC en toda América latina. Tampoco somos contrarios, en principio, a la ejecución de proyectos multinacionales. Pero establecemos una pauta fundamental e irrenunciable para medir la practicabilidad y utilidad de los acuerdos regionales:

favorecemos todos aquellos acuerdos regionales que contribuyan a fortalecer y acelerar el desarrollo integral de cada nación y nos oponemos a todos aquellos que reemplacen la noción de la integración nacional por el de una hipotética integración global fundada en la división internacional del trabajo. 
Para nosotros, la integración regional es una etapa superior de las integraciones nacionales. No queremos que la unidad de América latina sea la de naciones clébiles, fragmentadas y dependientes. Al revés, avizoramos el porvenir del continente como la hermandad de naciones fuertes, plenamente integradas y de creciente bienestar para sus pueblos.

Cuando nuestros compatriotas nos confirieron el honor de gobernar nuestro país, pusimos en práctica una vigorosa política de coordinación interamericana para acelerar el desarrollo de cada una de nuestras naciones. Con el presidente de Brasil, en Uruguayana y con el de Chile, en Viña del Mar, suscribimos declaxaciones inspiradas en una estrecha comunidad de intereses y aspiraciones. En viajes que realizamos durante nuestro mandato y aun antes de comenzar el período de gobierno, encontramos amplia coincidencia con los jefes de estado de nuestras repúblicas en cuanto a la urgencia de promover el crecimiento económico y la justicia social en América latina y de formar a tales efectos un frente común. En oportunidad de elaborarse el tratado de Montevideo, que dio nacimiento a la ALALC, nuestro gobierno colaboró eficazmente en su concertación.

Entendimos siempre que, además de la comunidad de intereses de todas nuestras repúblicas, las que pertenecen al Cono Sur del continente están especialmente vinculadas entre sí. Durante nuestro mandato nos empeñamos en reforzar los lazos que unen la Argentina con Uruguay, Paraguay, Bolivia, Chile, Perú y Brasil. La conferencia que sostuvimos con el presidente Quadros en Uruguayana (1961) nos dio oportunidad de concretar nuestras ideas sobre cooperación interamericana para el desarrollo. Las cancillerías de Río de Janeiro y de Buenos Aires aportaron a la entrevista de los presidentes un detallado $y$ serio examen de las perspectivas de intercambio entre ambos países. Los hombres de Itamaraty presentaron su punto de vista sobre ese comercio. Fundamentalmente consistia en asegurar la adquisición por el Brasil de granos argentinos a cambio de compras de material ferroviario, vehículos y maquinaria brasileños para la Argentina. Defendimos el interés argentino que no se satisfacía con la colocación de cereales en el mercado brasileño sino que aspiraba a exportar con destino a dicho mercado los productos de nuestra industria. En ese tiempo, la Angentina ejecutaba un plan de desarrollo que se traduciría en el autoabastecimiento de petróleo, en la instalación de grandes plantas que llegaron a quintuplicar la producción de automotores y caucho sintético y que duplicaron la producción de acero. La cooperación entre ambas naciones debia apoyarse en el hecho de que eran dos países en rápido proceso de integración e industrialización y que 
ofrecian mercados de creciente capacidad adquisitiva para absorber bienes industriales producidos en ambos. La Argentina no podía aceptar su condición de simple proveedora de productos del agro. El primer magistrado del país hermano comprendió nuestras razones y así quedó convenido en los documentos suscritos. Fijamos en Uruguayana una posición que ha sido invariable: el intercambio entre las repúblicas latinoamericanas debía propencler a su diversificación y enriquecimiento y rechazar todo intento de perpetuar las desigualdades entre ellas.

\section{DiÁlogos con KENNEDY}

Conversamos extensamente sobre el tema con el presidente Kennedy, de los Estados Unidos, en varias oportunidades. Cuando proclamó la Alianza para el Progreso, en nuestro caráctex de presidente de la Niación Argentina le enviamos una carta que iba más allá cle su formalidad protocolar.

Señalamos al ilustre estadista el peligro de que el programa de la Alianza equivocara su objeto. A nuestro juicio, se ponía demasiado énfasis en la asistencia para el desarrollo social, cuando debía recaer sobre el desarrollo económico. Sería un error, dijimos a Kennedy, canalizar los fondos de la Alianza hacia los proyectos sanitarios y educativos. Tal ayuda no genera factores reproductivos y dinámicos que permitan a nuestras naciones realizar la transformación de lás estructuras básicas de producción, únicas que garantizan un sostenido progreso social. Si la ayuda se concentra en la construcción de obras sanitarias, escuelas y hospitales, se sientan las condiciones de la perennidad de la beneficencia internacional; se mejoran los niveles de vida en forma superficial y contingente; pero el atraso económico perdura y los países beneficiados serían incapaces de proveer por sí mismos al bienestar de sus pueblos y serian siempre dependientes de la ayuda externa. Lo que nuestros pueblos necesitan, expresamos al presidente norteamericano, es cooperación financiera y técnica, de origen estatal y privado, para las inversiones reproductivas de la infraestructura económica y de la gran industria. Cuando nuestras naciones inicien el "despegue" hacia la industrialización, irán generando recursos $y$ nódulos sociales propios de las sociedades adelantadas y no necesitarán el socorro exterior para atender las necesidades de sus habitantes.

Igualmente nos empeñamos en llevar al ánimo de Kennedy, cuya genial visión del papel de su pais en el mundo fue trágicamente suprimida por sus asesinos, la sensación de urgencia de la cooperación internacional $-y$ por razones obvias, las de su país en primer térmi- 
no- para acelerar el proceso de industrialización de América latina, cuyas tensiones sociales no toleran una política de acumulación sobre la base de restringir el consumo. Refiriéndonos particularmente a la Argentina, pedí el apoyo político del presidente a las gestiones que hacía nuestro país para obtener créditos e inversiones en rubros tales como la hidroenergía, la siderurgia, los transportes y las comunicaciones. Rebatimos, en presencia de Kennedy, las objeciones de los economistas y financistas de su gobierno y de los organismos internacionales, que ponian en duda la economicidad o la rentabilidad de proyectos como el de la represa de lil Chocón-Cerros Colorados en Ia Patagonia argentina. Ya entonces comenzaban a tener auge las teorias de los proyectos multinacionales y de la complementación regional. El gobernante norteamericano comprendió nuestras razones y prometió apoyar las gestiones del gobierno argentino, en un comunicado conjunto que se firmó en Nueva York (196l).

\section{RIESGOS CONORETOS}

Infortunadamente, no se trata de insistir sobre problemas teóricos. Actualmente se producen hechos que corroboran la tendencia a considerar a América latina como una región, como un espacio económico, no como un continente formado por naciones. In cada uno de nuestros países se lanzan proyectos concretos que, en la práctica, consisten en hacer de unos países centros productores y de otros meros consumidores. Se ejecutan proyectos de represas y centrales de energia que se emplazan en Brasil y Paraguay para proveer a las naciones de la Cuenca del Plata. Capitales argentinos, con créditos internacionales, planifican la erección de una gran acería en Uruguay, para abastecer el mercado argentino. La Banca internacional parece inclinada a financiar industrias químicas -especialmente de celulosa y papelen Chile y Brasil, dejando de lado a la Argentina, a pesar de que nuestra producción maderera tiene enormes ventajas de economicidad sobre las de esas naciones, dado el más temprano rendimiento de sus plantaciones. En este esquema, la Argentina debería desarrollar solamente las industrias auxiliares de la economía agropecuaria (tractores, plaguicidas y abonos).

Es evidente que éste no puede ser un plan argentino, como no sería un plan chileno o boliviano el que intentara condenar a Chile y Bolivin a ser eternos proveedores de minerales.

\section{LA COYUNTURA MUNDIAL}

Reiteramos que no hay razón alguna que justifique tal abandono de las aspiraciones históricas de nuestras nacionalidades. Todas las cir- 
cunstancias de la maravillosa evolución del mundo contemporáneo favorecen la realización de esos anhelos. El ritmo sin precedentes del progreso científico y tecnológico está determinando, objetivamente, Ja universalización de sus conquïstas. El espacio ocupado por las naciones altamente desarrolladas ya no puede contener esa explosión dentro lite sus fronteras. La producción, los recursos financieros y técnicos del mundo adelantado, están obligados a desplegarse en un ámbito que abarque todo el planeta. El hecho de que la guerra total ya no sea una perspectiva probable se traduce en otra perspectiva más conforme con la razón y con la preservación de la especie: la de la competencia pacifica entre las grandes potencias de Oriente y Occidente. El campo natural donde se dirimirá esa competencia es el vasto y ávido sector del mundo rezagado, en el que viven dos tercios del género humano.

Caso típico de aprovechamiento de la competencia pacífica para e] desarrollo de un país subdesarrollado es el de Afganistán. Merced a la cooperación de organismos internacionales de crédito y a la ayuda bilateral que le prestan Rusia y Estados Unidos, esta nación, aislada durante siglos, participa ahora activamente en el comercio de la región. El gran problema que había que solucionar era el de los caminos de comunicación internos y de los puertos y fronteras con el mundo exterior. La Unión Soviética construyó las rutas y los puertos que corresponden al tráfico entre Rusia y Afganistán. Estados Unidos construyó los caminos del sur y del este del país, que lo ligan a la India y Pakistán. Actualmente, el legendario pais posee una de las mejores redes viales de la zona y comercia activamente con sus vecinos. En cuanto a ayuda financiera, también compiten Estados Unidos y. la Unión Soviética. Entre 19:62 y 1967 la ayuda rusa representó el $65 \%$ del total (229 millones de dólaies) contra $23 \%$ de los Estados Unidos (82 millones de dólares). Asimismo, el país ha recibido préstamos de Alemania Occidental (31 millones de dólares). El comercio exterior de Afganistán se orienta principalmente hacia la Unión Soviética, representando un tercio del total, pero también participan Estados Unidos, Pakistán, Alemania Occidental y Japón, en ese orden de importancia. La deuda exterior contraida para financiar el desarrollo, es del orden de los 546 millones de dólares, de los cuales se deben 382 millones a Rusia y 65 millones a Estados Únidos en préstamos a largo plazo. La deuda a corto plazo alcanza a otros 555 millones de dólares, que se divide entre Estados Unidos y la Unión Soviética: El próximo plan quinquenal estará concentrado en la inclustria, después de haberse satisfecho la primera prioridad en los planes anteriores: la red vial. 
Arluro Frondizi / El problema nacional de América Latina y ciertos esquemas de integración regional

Incumbe a nuestros pueblos latinoamericanos, mejor preparados que otros para lograr su rápida transformación, asumir la conciencia de esta inédita coyuntura de la historia y actuar en consecuencia. Sólo de la determinación nacional de nuestros países, de la decisión de sus clases dirigentes y de todos los sectores sociales, depende que esta oportunidad no se frustre.

Una manera de frustrarla seria aceptar la postergación de la integración nacional y abrazar la alternativa de la llamada complementación regional.

Si defendemos con convicción y energia la causa nacional de cada uno de nuestros paises, si encauzamos nuestra política internacional independiente al servicio de nuestras aspiraciones de desarrollo económico-social, si resistimos los esquemas de mediatización que sólo convienen a intereses extraños a nuestro destino, saldremos victoriosos de esta revolución, puesto que marcha en el sentido de la historia. La postergación, la tardanza, la derrota en el cumplimiento de los fines de esta empresa transformadora sólo serían imputables a nuestro renunciamiento. 